\title{
Writing a book review for Coaching: An International Journal of Theory, Research and Practice
}

\begin{abstract}
$\underline{\text { Abstract }}$
Book reviews form an important element of our offering to the readerships of this journal. We welcome critical book reviews that help readers decide whether or not the book will be of use to them either personally or professionally, and whether it might be worth considering purchasing the text. This article offers guidelines to potential book reviewers, and we invite your engagement and feedback as we develop the book review section of the journal.
\end{abstract}

Keywords: book review; critical; journal guidelines; peer review; feedback; texts' readership

\section{Practice Points}

- This submission is relevant to current and future contributors of book reviews. $\bullet$ We invite critical book reviews from authors who have a knowledge and understanding of the specific issues and theoretical concerns being discussed in the book. We also welcome reviewers who would be part of the target audience for any new book.

- Broadly, our advice to book reviewers is to: contribute a review that shows you have engaged in critically thinking about the content of the book, follow the journal's Instructions for Authors, and embrace the peer review process.

- It should offer a balanced view of the contents for the reader critiquing, rather than be overly critical.

\section{Introduction}

In recent years the journal has published advice and guidance for prospective contributors, which has covered: considering the rationale for a study (Rojon \& Saunders, 2012); using the literature critically (Saunders \& Rojon, 2011), explaining the research method (Saunders \& Rojon, 2014); tips for getting published in the journal (McDowall, 2015); and the peer review process (Rojon \& Saunders, 2015). This article builds on the latter two articles by giving advice about how to write a critical book review. It also covers some procedural matters.

\section{Critiquing a book}

A review (or "critique") of a book is not primarily a summary. Rather, it analyses, comments on and evaluates the work. It situates the work in the light of specific issues and theoretical concerns being discussed within the discipline. Your review should show recognition of the arguments and engage in critically thinking about the content. You may use examples from your own experience that resonate with the contents if you think this will assist the reader in gaining a rounded view of the book under review. To support your analysis and evaluation of the book, we recommend that you consider the following questions. 
(1) What is the specific topic of the book? What overall purpose does it seem to have? For what readership is it written? Look in the preface, acknowledgements, reference list and index for clues about where and how the piece was originally published, and about the author's background and position.

(2) Does the author state an explicit thesis? Does he or she noticeably have an axe to grind? What are the theoretical assumptions? Are they discussed explicitly? Again, look for statements in the preface, etc. and follow them up in the rest of the work.

(3) What exactly does the work contribute to coaching theory, research and practice? With what general problems and concepts does it engage?

(4) For edited books, what are the dominant themes with reference to specific chapters as appropriate? What are the implications of the book for research, policy, practice, or theory?

(5) What kinds of material does the work present? For example, does it present primary documents or secondary material, personal observations, literary analysis, quantitative data, biographical or historical accounts?

(6) If it is a textbook, in what courses can it be used? How clear is the book's structure and examples?

(7) Are the illustrations helpful? If there are no illustrations, should there have been?

(8) How is this material used to demonstrate and argue the thesis? As well as indicating the overall argumentative structure of the work, your review could quote or summarize specific passages to describe the author's presentation, including writing style and tone.

(9) Are there alternative ways of arguing from the same material? Does the author show awareness of them? In what respects does the author agree or disagree with them?

(10) What constructive comments can you make about the strength and weaknesses of the book?

(11) What theoretical issues and topics for further discussion does the work raise?

(12) In what way does the book compare with other works on this subject?

(13) What are your own reactions and considered opinions regarding the work?

(14) Who might you recommend read this work and why?

\section{Procedural matters}

(1) Book reviewers should adhere to the Instructions for Authors (Taylor and Francis Online), which cover structure, style guidelines and formatting. Unlike most articles in the journal, a book review does not require practice points because these should be clear from the review.

(2) The review should be between 500 and 1,200 words.

(3) The review should also include: 
- Author(s) or editor(s) first and last name(s) (please indicate if it is an edited book)

- Title of book

- Year of publication

- Place of publication

- Publisher

- Number of pages

- Price (please indicate paperback or hard cover) if available

- ISBN

\section{Conclusion}

Book reviewers bring their own individual perspectives when sharing their reflections, and use an assortment of approaches to stimulating debate and signposting the reader to new concepts and contexts. We offer these guidelines to help book reviewers analyse, comment on, and evaluate the work, and we welcome your feedback and engagement as we develop the book review section of the journal.

\section{$\underline{\text { References }}$}

Instructions for authors. (n.d.). ScholarOne manuscripts. Taylor \& Francis Online. Retrieved December 2016 from bit.ly/InstructionsforAuthors

McDowall, A. (2015). Getting published in Coaching: An International Journal of Theory, Research and Practice - our top 10 tips for enhancing your work. Coaching: An International Journal of Theory, Research and practice, 8(1), 61-64.

Rojon, C., \& Saunders, M. N. K. (2012). Formulating a convincing rationale for a research study. Coaching: An International Journal of Theory, Research and Practice, 5(1), 1-7.

Rojon, C., \& Saunders, M. N. K. (2015). Dealing with reviewers' comments in the publication process. Coaching: An International Journal of Theory, Research and Practice, 8(2), 169-180.

Saunders, M. N. K., \& Rojon C. (2011). On the attributes of a critical book review. Coaching: An International Journal of Theory, Research and Practice, 4(2), 156-162.

Saunders, M. N. K., \& Rojon, C. (2014). There's no madness in my method: Explaining how your coaching research findings are built on firm foundations. Coaching: An International Journal of Theory, Research and Practice, 7(1), 74-83. 